\title{
5 Research Square

\section{Impact of the Physician Orders for Life-Sustaining Treatment (POLST) Program Maturity Status on the Nursing Home Resident's Place of Death}

\author{
Aluem Tark ( $\nabla$ aluem-tark@uiowa.edu ) \\ University of lowa https://orcid.org/0000-0002-7671-8532 \\ Mansi Agarwal \\ Columbia University \\ Andrew Dick \\ RAND Corp \\ Jiyoun Song \\ Columbia University \\ Patricia Stone \\ Columbia University
}

Research article

Keywords: End-of-Life, Palliative Care, POLST, Elderly, Nursing Home

Posted Date: December 13th, 2019

DOI: https://doi.org/10.21203/rs.2.18816/v1

License: (c) (i) This work is licensed under a Creative Commons Attribution 4.0 International License.

Read Full License

Version of Record: A version of this preprint was published at American Journal of Hospice and Palliative Medicine ${ }^{\circledR}$ on September 3rd, 2020. See the published version at https://doi.org/10.1177/1049909120956650. 


\section{Abstract}

Background: The Physician Orders for Life-Sustaining Treatment program was developed to enhance quality of care delivered at end-of-life. Although positive impacts of the Physician Orders for LifeSustaining Treatment Program use have been identified, the association between a state's program maturity status and nursing home resident's likelihood of dying in their current care settings, nursing homes, remain unanswered.

Objective: Examine the impact of the Physician Orders for Life-Sustaining Program maturity status on nursing home residents' odds of dying in nursing homes.

Methods: Program maturity status data were linked with multiple datasets: Minimum Data Set, Vital Statistics Data, Master Beneficiary Summary File, Certification and Survey Provider Enhanced Reports, and Area Health Resource File. Stratifying residents on long-stay and short-stay, we used descriptive statistics and multivariable logistic regression models for total 595,152 individuals.

Results: Controlling for individual and contextual variables, long-stay nursing home residents living in states where the program was mature status had $20 \%$ increased odds of dying in nursing homes (OR: $1.20 ; \mathrm{Cl} 1.02-1.43)$ compared to those who resided in states with non-conforming status. Individuals residing in states with developing program status showed $11 \%$ increase in odds of dying in nursing homes (OR: 1.12; $\mathrm{Cl} 1.02-1.24)$ compared to non-conforming status. No significant difference was noted for short-stay nursing home residents.

Conclusion: Mature and developing maturity status were associated with greater likelihood of dying in nursing homes among long-stay residents. Our findings inform that a well-structured advance care planning program such as Physician Orders for Life-Sustaining Program enhances care outcomes among older adults living in nursing homes.

\section{Introduction}

Over 16,000 U.S. nursing homes (NHs) serve nearly 1.5 million U.S. individuals at any time.(1) An estimated 1 in 4 Americans will die in $\mathrm{NHs},(2,3)$ and this number is projected to increase making end-oflife (EoL) care important in this setting. $(2,4,5)$ Many experts have proposed domains of EoL care that can serve as quality indicators including: symptom management and care satisfaction,(6-8) advance care planning, $(7-9)$ aggressiveness of care, $(2,10)$ and place of death for long-stay residents. $(8,11)$ Place of death for $\mathrm{NH}$ residents as an EoL quality care marker needs to be carefully considered because of the differing care needs of long-stay NH compared to short-stay residents. $(12,13)$ Contrary to the goals of care in short-stay residents, which often focuses on rehabilitation, the goals of care for long-stay residents align towards optimizing quality of life and relief of suffering due to irreversible cognitive impairments, $(14-16)$ or progressively worsening physical impairments. $(17,18)$ For these residents, death in acute care facilities (e.g., emergency rooms or hospitals) is often deemed inappropriate, as hospital transfers are associated with physical and financial burdens,(19) adverse health outcomes,(20) and 
aggressive or unwanted medical interventions.(11, 21-24) For long-stay $\mathrm{NH}$ residents, hospital deaths have been identified as a marker for poor quality of EoL care. $(4,13,25-27)$

The Physician Orders for Life-Sustaining Treatment (POLST) program is an advance care planning paradigm developed by medical experts in Oregon.(28) As a voluntary tool, acknowledged as a program to help achieve high quality EoL care, it aims to facilitate EoL care discussions between a healthcare provider and a dying patients.(29-33)

To standardize the program, the national POLST program task force established 4 levels of program maturity status: mature, endorsed, developing, and non-conforming. $(28,34)$ Mature status indicates the highest endorsement level, where the POLST program (e.g., California's POLST) is part of the standard of care for individuals living with serious illnesses.(34) Endorsed status indicates that the state POLST program (e.g., New York's MOLST; M stands for medical) met key elements (e.g., having a single form for a state-wide usage), and developed strategies for ongoing education and quality assurance. $(28,34)$ Developing status indicates the POLST program (e.g., Ohio's MOLST) is at an initial stage of development, and working towards statewide implementation. Lastly, non-conforming status (e.g., Nebraska's POLST) indicates the POLST program either does not exist, or the state program does not meet the national POLST program endorsement criteria (e.g., no agreement on single form use).

While the use of POLST program was positively associated with increased hospice referrals, $(35,36)$ and EoL care discussions,(37-40) an association between a state's POLST program maturity status and $\mathrm{NH}$ residents outcomes is unclear. The aim of this study is to examine the impact of POLST maturity status on the $\mathrm{NH}$ death among elderly residents. We hypothesized that the higher POLST maturity status was positively associated with a greater likelihood of dying in the $\mathrm{NH}$ for long-stay residents.

\section{Method}

This national study is a retrospective, cross sectional analysis.

\section{Data sources}

We used data collected from a previously published POLST program environmental scan,(41) linked with national-level administrative datasets: 2014 Vital Statistics File, 2012-2013 Minimum Data Set 3.0 (MDS), 2014 Certification and Survey Provider Enhanced Reporting (CASPER), Area Health Resources File (AHRF) and the 2013 Master Beneficiary Summary File (MBSF).(41) All data were linked by facility identification or location.

The environmental scan included data on: a) state's POLST maturity status; b) POLST adoption year, c) year of current maturity status, and d) number of years it took to advance to the current maturity status. These data were collected for each U.S. state's POLST program maturity status, as of 2013. 
The Vital Statistics File was used to identify U.S. NH residents who died in 2013. Resident-level data were extracted from the MDS, federally mandated clinical assessments of $\mathrm{NH}$ residents residing in Centers of Medicare and Medicaid Services (CMS) certified nursing facilities.(42) Detailed health assessments are recorded upon admission, quarterly thereafter, and when any significant changes (i.e., transfer or death) occur; they contain demographic and health information (i.e., functional status).(43) We used the last available annual or the quarterly Omnibus Budget Reconciliation Act /Prospective Payment System (OBRA/PPS) assessment type prior to death for our long-stay group. For short-stay group, we utilized the PPS assessment type (i.e., 5-day, 14 day or 30 day scheduled assessment; whichever was the most recent). Resident characteristics extracted were: age at death, sex, race/ethnicity, and date of $\mathrm{NH}$ admission and discharge (when applicable); assessments on bed mobility, transfer, toilet use were extracted to compute the total activities of daily living (ADL) score for study sample.(44)

The CASPER dataset contains facility level information collected during the state annual inspections of NHs for CMS-required quality assurance.(45) Facility-level characteristics extracted included ownership, membership affiliation/ chain, bed size, occupancy rate, staffing and the presence of special units (i.e., Alzheimer's and/or hospice unit). Inclusion of presence of special units in NHs was guided by recent publications, $(46,47)$ which noted that having special units are associated with residents' health outcomes.

AHRF is a publicly available county-level dataset.(48) The following information were extracted: proportion elderly (> 65 years) population in county, and median household income. The MBSF data were used to identify Medicare beneficiaries with the following chronic conditions: Alzheimer's disease, dementia, chronic kidney disease (CKD), diabetes, cancer, and chronic obstructive pulmonary disease (COPD).(49)

\section{Study Sample}

We identified 1,009,372 unique individuals who died in 2013. The sampling process shown in Fig. 1. Exclusions were: individuals with no MDS in year 2012 or 2013, unable to merge with CASPER or AHRF data due to issues including inaccurate facility identifier or county code, no MBSF information, younger than 65 years of age, and living in the Virgin Islands. Our final study sample included 595,152 unique individuals. Guided by previous NH studies and based on our hypothesis,(50-52) we further classified our sample into long-stay (with consecutive length of stay equal or longer than 90 days) or short-stay.

\section{Outcome variables}

The primary outcome was place of death, dichotomized as $\mathrm{NH}$ death $=1$, non- $\mathrm{NH}$ death $=0$. $\mathrm{NH}$ death was defined on the last MDS assessment if a) resident's discharge placement indicated deceased, or b) MDS assessment type indicated death in facility. NH death was marked as no if a) MDS assessment type indicated discharge reporting and b) discharge to one of following settings: community; another $\mathrm{NH}$ facility; acute hospital; psychiatric hospital; inpatient rehab; Intellectual/ Development Disability (ID/DD) facility; hospice; long-term care hospital; or other. 


\section{Predictor variables}

The main predictor of interest was the POLST program maturity status.(41) Guided by previous $\mathrm{NH}$ studies, individual and contextual characteristics associated with place of death in $\mathrm{NHs}$ were also examined. Individual characteristics included were: resident's age, sex, race/ ethnicity, marital status, chronic conditions, and the total ADL score.(27, 50,53-55) Facility level predictors were: presence of special unit and bed size. Other contextual variables included: $\mathrm{NH}$ type, affiliation or chain status, occupancy rate, staffing, profit status, proportion of elderly population $\geq 65$, and median household income, $(48,56)$ setting, and geographic regions. $(11,25,48,53)$

\section{Analysis}

Descriptive statistics were used to summarize the study sample. Bivariate analyses were conducted to investigate differences in the study population between long and short-stay residents using chi-square and t-test statistic stratified by individuals with long and short-stays. Multivariable logistic regressions were conducted. To account for the non-independence of observations derived from repeated measures of $\mathrm{NH}$ facilities within the same county, we estimated county-clustered robust standard errors. Odds ratio (OR) and 95\% confidence intervals (Cl) were calculated. All analyses were conducted using SAS 9.4.

\section{Results}

\section{$\underline{\text { Resident level characteristics }}$}

Resident characteristics are presented in Table 1. The study sample included 595,152 unique elderly individuals, $48 \%$ long-stay $(n=285,888)$ and $52 \%$ short-stay residents $(n=309,264)$. These individuals resided in 6,241 NHs across the nation. Except for the presence of hospice unit within NH facilities, all other variables were significantly different across the long and short-stay groups ( $p<.0001)$. The residents were predominantly female (61\%), non-Hispanic White (85\%), and died between the ages of $86-90$ (24\%). The average age at death was 84 years (SD \pm 8.35 ). Nearly half $(49 \%)$ were in oldest age group, age 86 and older. Little over half ( $52 \%$ ) reported their marital status as widowed. The proportion of those widowed were higher among long-stay residents $(58 \%)$ than in short-stay $(46 \%)$ residents $(p<.0001)$. The most common chronic conditions were CHF (50\%) and CKD (48\%). Although the total proportion of sample residents who suffered from Alzheimer's disease were $29 \%$, the proportion was much higher among long-stay residents than short-stay residents ( $41 \%$ vs. $17 \%$, respectively, $p<0.001)$. The proportion of cancer patients was higher among short-stay residents than long-stay residents ( $19 \%$ vs. $8 \%$, respectively, $\mathrm{p}<.0001)$. Over half $(57 \%)$ of all residents died in $\mathrm{NH}$, and this was more common among long-stay residents than short-stay residents ( $76 \%$ vs $41 \%$ respectively, $p<.0001)$.

\section{$\underline{\text { State POLST program characteristics }}$}

The majority of states (59\%) had a POLST program with developing maturity status, followed by endorsed (35\%), non-conforming (5\%) and mature (1\%). Nearly all (95\%) of sample residents (i.e., $95 \%$ of 
all long-stay and $96 \%$ of all short-stay residents) were from the states where the POLST program had developing or higher maturity status.

\section{Contextual characteristics}

The contextual variables are presented in Table 2. Most NHs were for-profit status (72\%) and chain affiliated (57\%). More than half (59\%) of NHs were equipped with 100-199 beds, with an average occupancy rate of $84 \%( \pm 13.60)$. The was on average 0.74 hours per resident day for registered nurses $(S D \pm 0.43), 0.84$ hours per resident day for licensed practical nurses (SD \pm 0.35 ), and 2.16 hours per resident day for certified nursing assistant (SD \pm 0.65 ). Twenty two percent of all $\mathrm{NHs}$ were equipped with Alzheimer's unit; only $1 \%$ had a hospice unit $(1 \%)$. NHs were mainly located in the South (36\%) and in metropolitan areas (81\%). The average proportion of elderly population per county was $10 \%$ (SD \pm 3.27 ), and the median household income per county was $\$ 53,334.54$ (SD $\pm 13,957.46$ )

\section{Impact of POLST maturity status on $\mathrm{NH}$ death}

Table 3 shows the result of multivariable logistic regression. The odds of dying in NHs were $20 \%$ higher in states that had mature POLST programs, compared to states where the POLST program was nonconforming (OR: 1.20, 95\% Cl 1.02-1.43). Residents in a state where the POLST program had developing status had $12 \%$ (OR: $1.12,95 \% \mathrm{Cl} 1.02-1.24)$ increased odds of dying in NHs compared to residents in states where the POLST program was non-conforming. Endorsed POLST status showed $11 \%$ increase in $\mathrm{NH}$ death, but lacked significance (OR: 1.09, 95\% Cl 98-1.21). There was no difference for short-stay residents.

\section{Predictors of $\mathrm{NH}$ death by Stay Type}

In long-stay residents, older age groups had progressively higher likelihood of dying in NHs (ORs: 1.144.02). This association was similar in the short-stay group (ORs 1.04-2.88). Although odds of dying in $\mathrm{NHs}$ were not statistically different between the reference group (65-70 years) and the second youngest age group (71-75 years); all other age groups had progressively higher odds of dying in NHs (OR: 1.04, $1.19,1.35,1.63,1.91,2.23$ for age group 76-80, 81-85, 86-90, 91-95, 96-100, 101-110, respectively).

In both long and short-stay residents, individuals who were never married, divorced, separated, or widowed had higher likelihood of dying in NHs than married individuals (ORs: 1.10-1.57). In a long-stay group, separated marital status was the strongest predictor of $\mathrm{NH}$ deaths (OR: 1.27, 95\% $\mathrm{Cl}$ 1.14-1.40) compared to the married status. For the short-stay residents, never been married was the strongest predictor of $\mathrm{NH}$ deaths (OR: 1.52, 95\% Cl 1.47-1.57).

In the long-stay residents, compared to White race, all other race groups (i.e., African American, American Indian, Asian, Hispanic, Native Hawaiian/ Pacific Islander, 2 or more race) had lower odds of dying in NHs (ORs: $0.66-0.71$ ). In the short-stay residents, those who were Asian or multiple races had higher odds of dying in NHs (OR 1.22, 1.35, 95\% Cl 1.07-1.38, 1.15-1.58, respectively). 
COPD increased likelihood of death in NHs compared to those who did not have COPD (OR: $1.49,95 \% \mathrm{Cl}$ 1.45-1.53 long-stay; OR: 1.20, 95\% Cl 1.18-1.23 short-stay). Alzheimer's disease also increased likelihood of dying in NHs (OR: 1.49, 95\% Cl 1.44-1.54; OR: 1.45, 95\% Cl 1.42-1.48, respectively). An inverse relationship was noted in likelihood of dying in $\mathrm{NHs}$ for the $\mathrm{NH}$ residents suffering from cancer (OR 0.83 , 95\% Cl: $0.81-0.86$ for long stay; OR: $1.18,95 \% \mathrm{Cl} 1.15-1.20$ for short stay).

Facility characteristics associated with $\mathrm{NH}$ death were the presence of Alzheimer's unit (OR: $1.15,95 \% \mathrm{Cl}$ 1.11-1.20 for long-stay; OR 1.16, 95\% 95\% Cl 1.08-1.21 for short-stay), and the smaller NH facilities with less than 50 beds (OR: 1.16, 95\% Cl: 1.09, 1.24 for long-stay; OR1.12, 95\% Cl: 1.10-1.28 for short-stay), compared to NHs with 50-99 beds.

\section{Discussion}

\section{Main Findings}

This is the first study to examine the association between the POLST program maturity status and NH deaths. Controlling for individual and contextual characteristics, we found that mature (highest) and developing POLST maturity status were positively associated with greater odds of dying in NHs, among long-stay residents.

While the data used in this study do not allow for assessing individual preferences and completion of POLST forms, the significant relationship between the state's POLST maturity status and increased NH death in long-stay residents implies that the state-wide adoption of POLST can promote positive care outcomes. Spill-over is a term that explains the effects of an intervention on individuals who did not directly receive intervention, but who were connected to intervention recipients through social proximity. (57) It is often mentioned in NH studies where researchers witness an overall improvement of care outcome after initiating a new program that is designed for a target population (e.g., hospice program for dying patients).(50,57-62) Miller and colleagues reported that when a NH facility had greater hospice program enrollees, indicating higher exposure to specialized EoL care, resident outcomes such as better

management of pain, ${ }^{81}$ frequent pain assessments, ${ }^{79,81}$ and reduced number of burdensome transfers to hospitals were seen throughout all residents, regardless of their hospice enrollment status. $(61,63,64)$ This spillover phenomenon is thought to be caused by diffusion of knowledge.(65) That is, a newly implemented program or protocol generates new knowledge, which then fuels changes in the practice pattern or culture of institution, influencing care outcomes in general population. The pattern we observed, higher POLST maturity status and greater odds of dying in NHs among long-stay residents, may be due to increased knowledge generated with the initiation of state-wide adoption of the POLST program.

While we observed significant associations between NH deaths and the state's POLST status (mature and developing), the positive association between endorsed status and $\mathrm{NH}$ deaths lacked significance. The previous research on POLST has only looked at care outcomes measured from those who completed the 
POLST forms,(36, 39, 66-71) making it difficult to draw a comparison with our results. It is possible that there could be a plateau period, where relatively small efforts are made within the endorsed status to achieve mature status. It is also probable that NHs located in states with endorsed POLST status have an improved awareness on the importance of delivering specialized EoL care for dying patients, resulting in increased number of timely referrals to specialized EoL care facilities. Those NHs may also put more effort to identify dying patients' preferred place of death and allow them to be discharged near the time of death. Reasons behind the lack of significant association between the endorsed POLST status and NH deaths is an important question to be answered through future studies.

\section{Predictors of NH deaths}

Resident-level factors, specifically older age, White race, and living with chronic conditions (e.g., chronic obstructive pulmonary disease, Alzheimer's disease, and/ or dementia) were shown to increase the residents' odds of dying in NHs in both short and long-stay groups. Previous NH studies also reported similar findings: advanced age,(72-76) and chronic conditions as predictors of $\mathrm{NH}$ death for elderly residents living with serious illnesses. $(73,74,76-78)$

Although we noted a significant association between the race/ethnicity and dying in NHs in both stay groups, previous studies have mixed results. For example, in a recent study no significant associations were found between individual's race/ethnicity and the final place of death (e.g., hospital vs. non-hospital setting).(79) In another study, where authors examined the factors associated with in-hospital deaths among $\mathrm{NH}$ residents, it was noted that Black race was associated with a significantly higher risk of dying in hospitals when compared to their White counterparts.(80)

Men were at increased risk of $\mathrm{NH}$ death, in our short-stay group. While many studies have explored gender differences and the associated risk of mortality among $\mathrm{NH}$ residents, $(74,81-85)$ none reported specific location of death (e.g., $\mathrm{NH}$ vs. hospital). Moreover, the majority of available studies limited their study sample to disease-specific groups (e.g., Alzheimer's disease), $(82,83,85)$ or by their cognitive fuction. $(74$, 81)

Future researchers should use different measures for the level of POLST development such as total length of time since the POLST program was first initiated, or a composite score generated with different elements relevant to the POLST program (e.g., research efforts, staff awareness, actual number of POLST form completed). Second, future studies should examine the impact of POLST program maturity status on different outcomes (e.g., receipt of concordant interventions, number of hospice enrollments). Lastly, future research should also explore if different levels of maturity status are associated with best practices in EoL care, such as timely EoL discussions, family meetings and/or bereavement support.

\section{What this study adds}

In the last few years, a significant research efforts have been made to provide scientific evidence on benefits of high quality EoL care provided to vulnerable population. And previous studies unanimously support that best practices in EoL are those that maximize quality of remaining life, while minimizing 
avoidable care transfers. Results of this study call for the continued effort to adopt nationwide implementation of the POLST program that aims to deliver goal-concordant EoL care to elderly living with serious illnesses. It also calls for continued research efforts to identify best practices in EoL, and how best to deliver a type of care that aligns with dying patient's wishes, goals and values.

\section{Limitations of the study}

There are several limitations to this study. Rather than dichotomizing our outcome of interest as $\mathrm{NH}$ vs. non-NH death, examining other outcomes (i.e., death occurring in community) could have offered findings that were not discussed in our study. Plus, specifying place of death, beyond $\mathrm{NH}$ settings, could shed light to possible associations between the POLST maturity status and one's likelihood of dying at specific setting (e.g., home, $\mathrm{NH}$, hospital). However, this was not feasible with the datasets we used. For instance, the current MDS 3.0 assessment includes an item that can help identify if the resident's last discharge (before the date of death) was to the community, or other facilities such as acute care hospital. The challenge that exists in using community as a measure of deaths that occurred at home is that the term community in MDS 3.0 includes other settings (i.e., assisted living care settings, or group homes).

A similar problem arose when the patient's discharge placement indicated a discharge to a hospice setting. Although it may seem more appropriate that dying patient should receive specialized care at hospice settings, it was unclear whether it captures discharges to a separate hospice care center, or a hospice unit within the same facility.

Another limitation of our study is that due to the nature of cross-sectional analysis, the relationship we examined between the POLST maturity status and NH death can only be interpreted as an association, and not causation.

\section{Conclusion}

Controlling for individual and contextual variables, higher POLST maturity status is positively associated with greater likelihood of dying in NHs, among long-stay residents. Findings from our study adds to the body of science that well-structured advance care planning programs, such as POLST, can promote best practices in EoL. State-wide implementation of the POLST program, and continued efforts to meet high standards of quality EoL care (evidenced by higher maturity status) can result in positive health outcomes for elderly patients suffering from serious illnesses. State, or national-wide initiatives focusing on quality improvement at EoL should therefore be widely disseminated and adopted to provide best care possible for the most vulnerable populations.

\section{Declarations}

- Ethics approval and consent to participate 
Formal ethical approval was not required for this retrospective cohort study, as it did not affect the management of any human subjects.

\section{- Consent for publication}

Not applicable.

\section{- Availability of data and materials}

The datasets used and/or analyzed during the current study are available from the corresponding author on reasonable request.

\section{- Competing interests}

The authors declare that they have no competing interests.

\section{- Funding}

This research was funded by the Study of Infection Management and Palliative care at the End of Life (SIMP-EL, R01 NR013687), the Comparative and Cost-effectiveness Research Training for Nurse Scientists (CER2, T32 NR014205), and the Center for Improving Palliative Care for Vulnerable Adults with MCC (CIPC, P20 NR018072). Ms. A.T. is also funded by Jonas Center for Nursing and Veterans Health care.

\section{- Authors' contributions}

Author full name and initials: Aluem Tark (AT), Mansi Agarwal (MA), Andrew W. Dick (AD), Jiyoun Song (JS), Patricia W. Stone (PS)

\begin{tabular}{llllll} 
Contribution / Author initials & AT & MA & AD & JS & PW \\
\hline Substantial contribution to the concept or design of the work & X & X & & & X \\
\hline Acquisition, analysis or interpretation of data & $X$ & $X$ & $X$ & $X$ & \\
\hline Drafted the article & $X$ & & & \\
\hline
\end{tabular}

\begin{tabular}{lllllll} 
Resaved it critically for important intellectual content & & X & X & & $X$ \\
\hline Approved the version to be published & X & X & X & X & X \\
\hline Participated sufficiently in the work to take public responsibility for & X & X & X & X & X
\end{tabular}
appropriate portions of the content

- $\underline{\text { Acknowledgements }}$

Not applicable. 


\section{References}

1. Harris-Kojetin L, Sengupta M, Park-Lee E, Valverde R, Caffrey C, Rome V, et al. Long-Term Care Providers and Services Users in the United States: Data From the National Study of Long-Term Care Providers, 2013-2014. In: Statistics NCfH, editor.: Vital Health Stat; 2016.

2. Barbera L, Seow H, Sutradhar R, Chu A, Burge F, Fassbender K, et al. Quality Indicators of End-of-Life Care in Patients With Cancer: What Rate Is Right? Journal of oncology practice. 2015;11(3):e279-87.

3. Houser A. Long-Term Care. 2007 October 2007.

4. De Roo ML, Miccinesi G, Onwuteaka-Philipsen BD, Van Den Noortgate N, Van den Block L, Bonacchi $A$, et al. Actual and preferred place of death of home-dwelling patients in four European countries: making sense of quality indicators. PloS one. 2014;9(4):e93762-e.

5. Miyashita M, Morita T, Ichikawa T, Sato K, Shima Y, Uchitomi Y. Quality Indicators of End-of-Life Cancer Care from the Bereaved Family Members' Perspective in Japan. Journal of Pain and Symptom Management. 2009;37(6):1019-26.

6. Institute of Medicine (US) and National Research Council (US) National Cancer Policy Board. Quality of Care and Quality Indicators for End-of-Life Cancer Care: Hope for the Best, Yet Prepare for the Worst. Washington (DC): National Academies Press (US); 2001.

7. Donaldson MS, Field MJ. Measuring Quality of Care at the End of Life. Archives of Internal Medicine. 1998;158(2):121-8.

8. Wenger NS, Rosenfeld K. Quality Indicators for End-of-Life Care in Vulnerable Elders. Annals of Internal Medicine. 2001;135(8_Part_2):677-85.

9. Silvester W. Development and evaluation of an aged care specific Advance Care Plan. BMJ supportive \& palliative care.3(2):188-95.

10. Earle CC, Park ER, Lai B, Weeks JC, Ayanian JZ, Block S. Identifying Potential Indicators of the Quality of End-of-Life Cancer Care From Administrative Data. Journal of Clinical Oncology. 2003;21(6):1133-8.

11. Temkin-Greener $\mathrm{H}$, Zheng NT, Xing J, Mukamel DB. Site of death among nursing home residents in the United States: changing patterns, 2003-2007. Journal of the American Medical Directors Association. 2013;14(10):741-8.

12. Lepore M, Leland NE. Nursing Homes That Increased The Proportion Of Medicare Days Saw Gains In Quality Outcomes For Long-Stay Residents. Health affairs (Project Hope). 2015;34(12):2121-8.

13. Ziegler LE, Craigs CL, West RM, Carder P, Hurlow A, Millares-Martin P, et al. Is palliative care support associated with better quality end-of-life care indicators for patients with advanced cancer? A retrospective cohort study. 2018;8(1):e018284.

14. Wattmo C, Wallin ÅK. Early- versus Late-Onset Alzheimer Disease: Long-Term Functional Outcomes, Nursing Home Placement, and Risk Factors for Rate of Progression. Dementia and Geriatric Cognitive Disorders Extra. 2017;7(1):172-87.

15. Safarpour D. Nursing home and end-of-life care in Parkinson disease. Neurology.85(5):413-9. 
16. Hebert LE, Scherr PA, Bienias JL, Bennett DA, Evans DA. Alzheimer disease in the US population: prevalence estimates using the 2000 census. Archives of neurology. 2003;60(8):1119-22.

17. Lueckel SN. Population of Patients With Traumatic Brain Injury in Skilled Nursing Facilities: A Decade of Change. The journal of head trauma rehabilitation. 2019;34(1):E39-E45.

18. Jerez-Roig J. Prevalence of urinary incontinence and associated factors in nursing home residents Urinary Incontinence in Nursing Home Residents. Neurourology and urodynamics.35(1):102-7.

19. Gabbe B, Lowthian J, Dwyer R, Stoelwinder JU. A systematic review of outcomes following emergency transfer to hospital for residents of aged care facilities. Age and Ageing. 2014;43(6):75966.

20. Laurent M, Bories PN, Le Thuaut A, Liuu E, Ledudal K, Bastuji-Garin S, et al. Impact of Comorbidities on Hospital-Acquired Infections in a Geriatric Rehabilitation Unit: Prospective Study of 252 Patients. Journal of the American Medical Directors Association. 2012;13(8):760.e7-.e12.

21. Gruneir A, Mor V, Weitzen S, Truchil R, Teno J, Roy J. Where people die: a multilevel approach to understanding influences on site of death in America. Medical care research and review : MCRR. 2007;64(4):351-78.

22. Lamberg JL, Person CJ, Kiely DK, Mitchell SL. Decisions to hospitalize nursing home residents dying with advanced dementia. J Am Geriatr Soc. 2005;53(8):1396-401.

23. Morley JE. Opening Pandora's Box: The Reasons Why Reducing Nursing Home Transfers to Hospital are so Difficult. Journal of the American Medical Directors Association. 2016;17(3):185-7.

24. van der Steen JT, Lemos Dekker N, Gijsberts M-JHE, Vermeulen LH, Mahler MM, The BA-M. Palliative care for people with dementia in the terminal phase: a mixed-methods qualitative study to inform service development. BMC Palliative Care. 2017;16(1):28.

25. Temkin-Greener H, Zheng NT, Norton SA, Quill T, Ladwig S, Veazie P. Measuring end-of-life care processes in nursing homes. The Gerontologist. 2009;49(6):803-15.

26. Saliba D, Kington R, Buchanan J, Bell R, Wang M, Lee M, et al. Appropriateness of the decision to transfer nursing facility residents to the hospital. J Am Geriatr Soc. 2000;48(2):154-63.

27. Teno JM, Gozalo PL, Bynum JPW, Leland NE, Miller SC, Morden NE, et al. Change in End-of-Life Care for Medicare Beneficiaries: Site of Death, Place of Care, and Health Care Transitions in 2000, 2005, and 2009End-of-Life Care for Medicare Beneficiaries. JAMA. 2013;309(5):470-7.

28. National POLST paradigm. POLST Paradigm Fundamentals www.polst.org2019 [Available from: https://polst.org/about-the-national-polst-paradigm/what-is-polst/.

29. Oregon POLST. Oregon POLST History [Available from: https://oregonpolst.org/history.

30. Fromme EK, Zive D, Schmidt TA, Cook JN, Tolle SW. Association between Physician Orders for LifeSustaining Treatment for Scope of Treatment and in-hospital death in Oregon. J Am Geriatr Soc. 2014;62(7):1246-51.

31. Tuck KK, Zive DM, Schmidt TA, Carter J, Nutt J, Fromme EK. Life-sustaining treatment orders, location of death and co-morbid conditions in decedents with Parkinson's disease. Parkinsonism \& 
related disorders. 2015;21(10):1205-9.

32. Hickman SE. Use of the Physician Orders for Scope of Treatment Program in Indiana Nursing Homes Use of Indiana POST in Nursing Homes. Journal of the American Geriatrics Society (JAGS).66(6):1096-100.

33. Kim H. Physician Orders for Life-Sustaining Treatment for nursing home residents with dementia. Journal of the American Association of Nurse Practitioners.27(11):606-14.

34. National POLST paradigm. Program Regonition [Available from: http://polst.org/programrecognition/?pro $\underline{1 / 41}$.

35. Knestrick MW, Pedraza SL, Culp S, Falkenstine EC, Moss AH. Benefits of physician orders for scope of treatment (POST) forms on end-of-life care in cancer patients: Insights from the West Virginia registry. Journal of Clinical Oncology. 2016;34(15_suppl):10006-.

36. Nugent SM, Slatore CG, Ganzini L, Golden SE, Zive D, Vranas KC, et al. POLST Registration and Associated Outcomes Among Veterans With Advanced-Stage Lung Cancer. American Journal of Hospice and Palliative Medicine®. 2019:1049909118824543.

37. Kim H, Ersek M, Bradway C, Hickman SE. Physician Orders for Life-Sustaining Treatment for nursing home residents with dementia. Journal of the American Association of Nurse Practitioners. 2015;27(11):606-14.

38. Lum HD. Advance care planning in the elderly. The Medical clinics of North America.99(2):391-403.

39. Sebastian P. Healthcare Professionals' Perceptions and Use of the Provider Orders for Life-Sustaining Treatment (POLST) Form. Journal of the American Medical Directors Association.18(3):B22-B3.

40. Braun UK. Experiences with POLST: Opportunities for Improving Advance Care Planning. Journal of General Internal Medicine. 2016;31(10):1111-2.

41. Tark A, Agarwal M, Dick AW, Stone PW. Variations in Physician Orders for Life-Sustaining Treatment Program across the Nation: Environmental Scan. Journal of palliative medicine. 2019.

42. Morley JE. Minimum Data Set 3.0: a giant step forward. Journal of the American Medical Directors Association.14(1):1-3.

43. Saliba D, Buchanan J. Making the Investment Count: Revision of the Minimum Data Set for Nursing Homes, MDS 3.0. Journal of the American Medical Directors Association. 2012;13(7):602-10.

44. Wysocki A, Thomas KS, Mor V. Functional Improvement Among Short-Stay Nursing Home Residents in the MDS 3.0. Journal of the American Medical Directors Association. 2015;16(6):470-4.

45. Lucas JA, Bowblis JR. CMS Strategies To Reduce Antipsychotic Drug Use In Nursing Home Patients With Dementia Show Some Progress. Health Aff (Millwood). 2017;36(7):1299-308.

46. Hunnicutt JN, Tjia J, Lapane KL. Hospice Use and Pain Management in Elderly Nursing Home Residents With Cancer. Journal of Pain and Symptom Management. 2017;53(3):561-70.

47. Dick AW, Bell JM, Stone ND, Chastain AM, Sorbero M, Stone PW. Nursing home adoption of the National Healthcare Safety Network Long-term Care Facility Component. Am J Infect Control. 2019;47(1):59-64. 
48. Holup AA, Gassoumis ZD, Wilber KH, Hyer K. Community Discharge of Nursing Home Residents: The Role of Facility Characteristics. Health services research. 2016;51(2):645-66.

49. Centers for Medicare \& Medicaid Services. Master Beneficiary Summary File (MBSF) LDS 2018 [updated Aug 24 2018; cited 2019 Jan 2]. Available from: https://www.cms.gov/Research-StatisticsData-and-Systems/Files-for-Order/LimitedDataSets/MBSF-LDS.html.

50. Miller SC, Lima JC, Intrator O, Martin E, Bull J, Hanson LC. Palliative Care Consultations in Nursing Homes and Reductions in Acute Care Use and Potentially Burdensome End-of-Life Transitions. 2016;64(11):2280-7.

51. Phillips LJ, Birtley NM, Petroski GF, Siem C, Rantz M. An observational study of antipsychotic medication use among long-stay nursing home residents without qualifying diagnoses. 2018;25(8):463-74.

52. Jennifer T, Marisa D, L. GJ. Advance Directives among Nursing Home Residents with Mild, Moderate, and Advanced Dementia. 2018;21(1):16-21.

53. Temkin-Greener H, Lee T, Caprio T, Cai S. Rehabilitation Therapy for Nursing Home Residents at the End-of-Life. Journal of the American Medical Directors Association. 2018.

54. Carpenter GI, Hastie CL, Morris JN, Fries BE, Ankri J. Measuring change in activities of daily living in nursing home residents with moderate to severe cognitive impairment. BMC Geriatrics. 2006;6(1):7.

55. Grabowski DC, Feng Z, Hirth R, Rahman M, Mor V. Effect of nursing home ownership on the quality of post-acute care: An instrumental variables approach. Journal of Health Economics. 2013;32(1):1221.

56. Cohen CC, Engberg J, Herzig CTA, Dick AW, Stone PW. Nursing Homes in States with Infection Control Training or Infection Reporting Have Reduced Infection Control Deficiency Citations. Infection Control \&\#x0026; Hospital Epidemiology. 2015;36(12):1475-6.

57. Benjamin-Chung J, Abedin J, Berger D, Clark A, Jimenez V, Konagaya E, et al. Spillover effects on health outcomes in low- and middle-income countries: a systematic review. International journal of epidemiology. 2017;46(4):1251-76.

58. Nanda A, Martin EW, Welch LC, Miller SC. Referral and Timing of Referral to Hospice Care in Nursing Homes: The Significant Role of Staff Members. The Gerontologist. 2008;48(4):477-84.

59. Pearson ML, Wyte-Lake T, Bowman C, Needleman J, Dobalian A. Assessing the impact of academicpractice partnerships on nursing staff. BMC Nursing. 2015;14(1):28.

60. Sprangers S, Dijkstra K, Romijn-Luijten A. Communication skills training in a nursing home: effects of a brief intervention on residents and nursing aides. Clinical interventions in aging. 2015;10:311-9.

61. Miller SC, Mor V, Wu N, Gozalo P, Lapane K. Does receipt of hospice care in nursing homes improve the management of pain at the end of life? J Am Geriatr Soc. 2002;50(3):507-15.

62. Zheng NT, Mukamel DB, Friedman B, Caprio TV, Temkin-Greener H. The effect of hospice on hospitalizations of nursing home residents. Journal of the American Medical Directors Association. 2015;16(2):155-9. 
63. Miller SC, Gozalo P, Mor V. Hospice enrollment and hospitalization of dying nursing home patients. The American journal of medicine. 2001;111(1):38-44.

64. Miller SC, Mor VNT. The role of hospice care in the nursing home setting. Journal of palliative medicine. 2002;5(2):271-7.

65. Miller SC, Lima JC, Thompson SA. End-of-Life Care in Nursing Homes with Greater versus Less Palliative Care Knowledge and Practice. Journal of palliative medicine. 2015;18(6):527-34.

66. Lebenthal J, Barile D, Sedhom R. Does use of the POLST form implicate overall care for patients with advanced cancer syndromes? Journal of Clinical Oncology. 2017;35(31_suppl):15-

67. Ballou JH, Dewey E, Zonies DH. Elderly Patients Presenting to a Level I Trauma Center with a POLST form: A Propensity-Matched Analysis. The journal of trauma and acute care surgery. 2019.

68. Lee MA, Brummel-Smith K, Meyer J, Drew N, London MR. Physician orders for life-sustaining treatment (POLST): outcomes in a PACE program. Program of All-Inclusive Care for the Elderly. J Am Geriatr Soc. 2000;48(10):1219-25.

69. Guidelines for Emergency Physicians on the Interpretation of Physician Orders for Life-Sustaining Therapy (POLST). Annals of emergency medicine. 2017;70(1):122-5.

70. Lammers AJ, Zive DM, Tolle SW, Fromme EK. The Oncology Specialist's Role in POLST Form Completion. The American journal of hospice \& palliative care. 2018;35(2):297-303.

71. Schmidt TA, Hickman SE, Tolle SW, Brooks HS. The Physician Orders for Life-Sustaining Treatment program: Oregon emergency medical technicians' practical experiences and attitudes. J Am Geriatr Soc. 2004;52(9):1430-4.

72. Perrels AJ, Fleming J, Zhao J, Barclay S, Farquhar M, Buiting HM, et al. Place of death and end-of-life transitions experienced by very old people with differing cognitive status: Retrospective analysis of a prospective population-based cohort aged 85 and over. Palliative Medicine. 2013;28(3):220-33.

73. Porock D, Oliver DP, Zweig S, Rantz M, Mehr D, Madsen R, et al. Predicting death in the nursing home: development and validation of the 6-month Minimum Data Set mortality risk index. The journals of gerontology Series A, Biological sciences and medical sciences. 2005;60(4):491-8.

74. Drageset J, Eide GE, Ranhoff AH. Mortality in nursing home residents without cognitive impairment and its relation to self-reported health-related quality of life, sociodemographic factors, illness variables and cancer diagnosis: a 5-year follow-up study. Quality of Life Research. 2013;22(2):31725.

75. Van Rensbergen G, Nawrot TS, Van Hecke E, Nemery B. Where do the elderly die? The impact of nursing home utilisation on the place of death. Observations from a mortality cohort study in Flanders. BMC Public Health. 2006;6(1):178.

76. Vossius C, Selbæk G, Šaltyte Benth J, Bergh S. Mortality in nursing home residents: A longitudinal study over three years. PLOS ONE. 2018;13(9):e0203480.

77. Zhang X, Dou Q, Zhang W, Wang C, Xie X, Yang Y, et al. Frailty as a Predictor of All-Cause Mortality Among Older Nursing Home Residents: A Systematic Review and Meta-analysis. Journal of the American Medical Directors Association. 2019. 
78. Hjaltadottir I, Hallberg IR, Ekwall AK, Nyberg P. Predicting mortality of residents at admission to nursing home: a longitudinal cohort study. BMC health services research. 2011;11:86.

79. Salomon S, Chuang E, Bhupali D, Labovitz D. Race/Ethnicity as a Predictor for Location of Death in Patients With Acute Neurovascular Events. The American journal of hospice \& palliative care. 2018;35(1):100-3.

80. Kwak J, Haley WE, Chiriboga DA. Racial Differences in Hospice Use and In-Hospital Death Among Medicare and Medicaid Dual-Eligible Nursing Home Residents. The Gerontologist. 2008;48(1):32-41.

81. Sund-Levander M, Grodzinsky E, Wahren LK. Gender differences in predictors of survival in elderly nursing-home residents: a 3-year follow up. Scandinavian Journal of Caring Sciences. 2007;21(1):1824.

82. Lapane KL, Gambassi G, Landi F, Sgadari A, Mor V, Bernabei R. Gender differences in predictors of mortality in nursing home residents with AD. Neurology. 2001;56(5):650.

83. Fernandez HH, Lapane KL. Predictors of mortality among nursing home residents with a diagnosis of Parkinson's disease. Medical science monitor : international medical journal of experimental and clinical research. 2002;8(4):Cr241-6.

84. Hoffmann F, Allers K. Age and sex differences in hospitalisation of nursing home residents: a systematic review. BMJ Open. 2016;6(10):e011912.

85. Lee JS, Chau PP, Hui E, Chan F, Woo J. Survival prediction in nursing home residents using the Minimum Data Set subscales: ADL Self-Performance Hierarchy, Cognitive Performance and the Changes in Health, End-stage disease and Symptoms and Signs scales. European journal of public health. 2009;19(3):308-12.

\section{Tables}

Table 1. Description of Resident Level Characteristics and Bivariate Associations by Stay Type. 


\begin{tabular}{|c|c|c|c|c|}
\hline Characteristic & $\begin{array}{l}\text { Long-stay residents } \\
\qquad(\mathrm{n}=285,888)\end{array}$ & $\begin{array}{l}\text { Short-stay residents } \\
\qquad(\mathrm{n}=309,264)\end{array}$ & $\begin{array}{l}\text { Total sample } \\
(\mathrm{n}=595,152)\end{array}$ & Pvalue $^{1}$ \\
\hline \multicolumn{5}{|c|}{ Individual characteristics, n (\%) } \\
\hline \multirow{3}{*}{$\begin{array}{c}\underline{\text { Sex }} \\
\text { Female } \\
\text { Race/ Ethnicity }\end{array}$} & & & & $<.0001$ \\
\hline & $194,161(67.92)$ & $167,473(54.15)$ & $361,634(60.77)$ & \\
\hline & & & & $<.0001$ \\
\hline \multirow{3}{*}{$\begin{array}{l}\text { African American } \\
\text { American Indian } \\
\text { Asian }\end{array}$} & $28,775(10.24)$ & $25,838(8.61)$ & $54,613(9.39)$ & \\
\hline & $659(0.23)$ & $653(0.22)$ & $1312(0.23)$ & \\
\hline & $3,891(1.38)$ & $4,204(1.40)$ & $8,095(1.39)$ & \\
\hline \multirow{3}{*}{$\begin{array}{c}\text { Hispanic } \\
\text { Two or more race } \\
\text { Native Hawaiian }\end{array}$} & $9,769(3.47)$ & $9,282(3.09)$ & 19,051 (3.28) & \\
\hline & $577(0.21)$ & $598(0.20)$ & $1,175(0.20)$ & \\
\hline & $272(0.1)$ & $344(0.11)$ & $616(0.11)$ & \\
\hline \multirow{2}{*}{\multicolumn{5}{|c|}{$\begin{array}{c}\text { Non-Hispanic White } \\
\text { Age at death }\end{array}$}} \\
\hline & & & & \\
\hline $65-70$ & $17,237(6.03)$ & $31,332(10.13)$ & $48,569(8.08)$ & $<.0001$ \\
\hline $71-75$ & $21,330(7.46)$ & $34,395(11.12)$ & $55,725(9.29)$ & \\
\hline $76-80$ & $33,574(11.74)$ & $46,933(15.18)$ & $80,507(13.46)$ & \\
\hline $81-85$ & $55,148(19.29)$ & $65,855(21.29)$ & $121,003(20.29)$ & \\
\hline $86-90$ & $71,612(25.05)$ & $71,140(23.00)$ & $142,752(24.03)$ & \\
\hline $91-95$ & $58,318(20.40)$ & $42,569(14.64)$ & $100,887(17.52)$ & \\
\hline $96-100$ & $23,824(8.33)$ & $12,765(4.13)$ & $36,589(6.23)$ & \\
\hline $101-110$ & $4,845(1.69)$ & $1,575(0.51)$ & $6,120(1.10)$ & \\
\hline \multicolumn{5}{|l|}{ Marital Status } \\
\hline \multirow{6}{*}{$\begin{array}{c}\text { Divorced } \\
\text { Married } \\
\text { Never Married } \\
\text { Separated } \\
\text { Widowed } \\
\text { Chronic Conditions }\end{array}$} & $25,933(9.18)$ & $24,509(8.12)$ & $50,442(8.64)$ & $<.0001$ \\
\hline & $62,637(22.18)$ & $111,973(37.12)$ & $174,610(29.89)$ & \\
\hline & $27,671(9.80)$ & $22,751(7.54)$ & $50,422(8.63)$ & \\
\hline & $2,579(0.91)$ & $2,418(0.80)$ & $4,997(0.86)$ & \\
\hline & $163,596(57.93)$ & $140,027(46.42)$ & $303,623(51.98)$ & \\
\hline & & & & \\
\hline Alzheimer & $116,110(40.61)$ & $53,939(17.44)$ & $170,049(28.57)$ & $<.0001$ \\
\hline \multirow{3}{*}{$\begin{array}{l}\text { Dementia } \\
\text { CKD } \\
\text { CHF }\end{array}$} & $103,570(36.23)$ & $81,750(26.43)$ & $185,320(31.14)$ & $<.0001$ \\
\hline & $122,948(43.01)$ & $162,208(52.45)$ & $285,156(47.91)$ & $<.0001$ \\
\hline & $140,126(49.01)$ & $159,924(51.71)$ & $300,050(50.42)$ & $<.0001$ \\
\hline \multirow{4}{*}{$\begin{array}{c}\text { Diabetes } \\
\text { Cancer } \\
\text { COPD } \\
\text { Death in NH } \\
\end{array}$} & $109,363(38.25)$ & $109,918(35.54)$ & $219,281(36.84)$ & $<.0001$ \\
\hline & $23,294(8.15)$ & $58,484(18.81)$ & $81,478(13.69)$ & $<.0001$ \\
\hline & $66,051(23.10)$ & $99,614(32.21)$ & $165,665(27.84)$ & $<.0001$ \\
\hline & $216,182(75.62)$ & $125542(40.59)$ & 341724 (57.42) & $<.0001$ \\
\hline
\end{tabular}

Note: ADL: activities of daily living; CKD: chronic kidney disease; COPD: chronic obstructive pulmonary disease; LPN: licensed practical nurse; NH: nursing home; SD: standard deviation;

1: P value from chi-square tests for categorical variables, and t test for continuous variables

$\square$ ADL score range 4 to 18 ( 4 = independent, 18 = total dependency)

Table 2. Description of NH Sample and Bivariate Associations, by Stay Type. 
Characteristic Long-stay residents Short-stay residents

$(n=285,888)$

$(n=309,264)$

$(n=595,152)$

\begin{tabular}{|c|c|c|c|c|}
\hline \multicolumn{5}{|c|}{ Independent variable, $\mathbf{n}(\%)$} \\
\hline \multirow{2}{*}{$\frac{\text { POLST maturity status }}{\text { Mature }}$} & & & & $<.0001$ \\
\hline & $3,377(1.18)$ & $4,829(1.56)$ & $8,206(1.38)$ & \\
\hline \multirow{3}{*}{$\begin{array}{c}\text { Endorsed } \\
\text { Developing } \\
\text { Non-conforming }\end{array}$} & $101,632(35.55)$ & $108,566(35.10)$ & $210,198(35.32)$ & \\
\hline & $167,370(58.54)$ & $182,356(58.96)$ & $349,726(58.76)$ & \\
\hline & $13,509(4.73)$ & $13,513(4.37)$ & $27,022(4.54)$ & \\
\hline \multirow[b]{2}{*}{ Facility type } & \multicolumn{3}{|c|}{ Facility characteristics, $\mathbf{n}(\%)$} & \\
\hline & & $<.0001$ \\
\hline \multirow{4}{*}{$\begin{array}{c}\text { For-profit } \\
\text { Non-profit } \\
\text { Government } \\
\text { Affiliation/ Chain }\end{array}$} & $198,680(69.50)$ & $230,622(74.57)$ & $429,302(72.13)$ & \\
\hline & $70,245(24.57)$ & $69,320(22.41)$ & $139,565(23.45)$ & \\
\hline & $16,963(5.93)$ & $9,322(3.01)$ & $26,285(4.42)$ & \\
\hline & $154,981(54.21)$ & $184,326(59.60)$ & $339,307(57.01)$ & $<.0001$ \\
\hline Bed size & & & & $<.0001$ \\
\hline$<50$ & $8,779(3.11)$ & $10,844(3.55)$ & $19,623(3.34)$ & \\
\hline $50-99$ & $71,803(25.44)$ & $75,284(24.63)$ & $147,087(25.02)$ & \\
\hline \multirow{3}{*}{$\begin{array}{c}100-199 \\
>200 \\
\text { Occupancy rate }\end{array}$} & $161,173(57.11)$ & $184,343(60.32)$ & $345,516(58.78)$ & \\
\hline & $40,462(14.34)$ & $35,135(11.50)$ & $35,135(11.50)$ & \\
\hline & $85.06(12.89)$ & $83.82(14.19)$ & $84.41(13.60)$ & $<.0001$ \\
\hline$\frac{\text { Occupancy rate }}{\text { Staffing }}$ & & & & \\
\hline $\mathrm{RN}$ & $0.69(0.34)$ & $0.81(0.49)$ & $0.75(0.43)$ & $<.0001$ \\
\hline LPN & $0.82(0.33)$ & $0.86(0.37)$ & $0.84(0.35)$ & $<.0001$ \\
\hline \multirow{3}{*}{$\begin{array}{c}\text { CNA } \\
\text { Occupancy rate } \\
\text { Special unit }\end{array}$} & $2.44(0.60)$ & $2.48(0.69)$ & $2.16(0.65)$ & $<.0001$ \\
\hline & $85.06(12.89)$ & $83.82(14.19)$ & $84.41(13.60)$ & $<.0001$ \\
\hline & & & & \\
\hline \multirow{2}{*}{$\begin{array}{l}\text { Alzheimer's unit } \\
\text { Hospice unit }\end{array}$} & $62,853(21.99)$ & $54,355(17.58)$ & $117,208(19.69)$ & $<.0001$ \\
\hline & $2,904(1.02)$ & $3,279(1.06)$ & $6,183(1.04)$ & 0.09 \\
\hline \multirow{3}{*}{$\begin{array}{l}\text { Elderly proportion } \\
\text { Median household income }\end{array}$} & \multicolumn{3}{|c|}{ County level characteristics, mean (SD) } & \\
\hline & $10.11(3.86)$ & $9.95(3.59)$ & $10.03(3.72)$ & $<.0001$ \\
\hline & $52484.29(13670.26)$ & 54120.59 & $53334.54(13957.46)$ & $<.0001$ \\
\hline \multirow{6}{*}{$\begin{array}{c}\text { Setting } \\
\text { Metropolitan } \\
\text { Urban } \\
\text { Rural } \\
\text { Geographic region }\end{array}$} & \multicolumn{3}{|c|}{ County level characteristics, $\mathbf{n}(\%)$} & \\
\hline & & & & $<.0001$ \\
\hline & $221548(77.50)$ & $261631(84.60)$ & 79 (81.19) & \\
\hline & $57740(20.20)$ & $43867(14.19)$ & $07(17.07)$ & \\
\hline & $6569(2.30)$ & $3750(1.21)$ & $319(1.73)$ & \\
\hline & & & & $<.0001$ \\
\hline Midwest & $82,204(28.75)$ & 79,062 (25.57) & $66(27.10)$ & \\
\hline Northeast & $72,731(25.44)$ & $71,675(23.18)$ & $06(24.27)$ & \\
\hline South & $102,059(35.70)$ & $110,709(35.80)$ & 68 (35.75) & \\
\hline West & $28,891(10.11)$ & $47,767(15.45)$ & 58 (12.88) & \\
\hline
\end{tabular}

Note: CNA: certified nursing assistance; LPN: licensed practical nurse; NH: nursing home; POLST: physician orders for life-sustaining treatment; SD:

standard deviation;

*: measured in full-time equivalent hours per resident per day

1: $P$ value from chi-square tests for categorical variables, and t test for continuous variables

Table 3. Multivariable logistic regression model by NH stay type 


\begin{tabular}{|c|c|c|c|c|}
\hline Predictors & \multicolumn{2}{|c|}{ Long-Stay Residents } & \multicolumn{2}{|c|}{ Short-Stay Residents } \\
\hline & OR & $(95 \% \mathrm{Cl})$ & OR & $(95 \% \mathrm{Cl})$ \\
\hline \multicolumn{5}{|l|}{ POLST maturity status } \\
\hline Mature & 1.20 & $(1.02-1.43)$ & 0.90 & $(0.75-1.09)$ \\
\hline Endorsed & 1.09 & $(0.98-1.21)$ & 1.12 & $(0.99-1.26)$ \\
\hline Developing & 1.12 & $(1.02-1.24)$ & 0.97 & $(0.86-1.10)$ \\
\hline Non-Conforming & \multicolumn{2}{|c|}{ Reference } & \multirow{2}{*}{\multicolumn{2}{|c|}{ Reference }} \\
\hline Age (in years) & & & & \\
\hline $65-70$ & \multicolumn{2}{|c|}{ Reference } & \multicolumn{2}{|c|}{ Reference } \\
\hline $71-75$ & 1.14 & $(1.07-1.20)$ & 1.008 & $(0.98-1.04)$ \\
\hline $76-80$ & 1.27 & $(1.22-1.33)$ & 1.09 & $(1.04-1.13)$ \\
\hline $81-85$ & 1.46 & (1.41-1.52) & 1.23 & $(1.19-1.27)$ \\
\hline $86-90$ & 1.71 & $(1.65-1.78)$ & 1.41 & $(1.35-1.47)$ \\
\hline $91-95$ & 2.12 & $(2.03-2.21)$ & 1.70 & $(1.63-1.78)$ \\
\hline $96-10$ & 2.74 & $(2.60-2.88)$ & 2.02 & $(1.91-2.14)$ \\
\hline $101-110$ & 4.02 & (3.63-4.44) & 2.54 & $(2.23-2.88)$ \\
\hline \multicolumn{5}{|l|}{ Sex } \\
\hline Female & \multicolumn{2}{|c|}{ Reference } & \multicolumn{2}{|c|}{ Reference } \\
\hline \multirow{2}{*}{\multicolumn{5}{|c|}{\begin{tabular}{r|r} 
Mrale & 0.995 \\
Marital Status &
\end{tabular}}} \\
\hline & & & & \\
\hline Married & \multicolumn{2}{|c|}{ Reference } & \multicolumn{2}{|c|}{ Reference } \\
\hline Never Married & 1.14 & $(1.10-1.19)$ & 1.52 & $(1.47-1.57)$ \\
\hline Divorce & 1.17 & $(1.13-1.22)$ & 1.38 & $(1.33-1.43)$ \\
\hline Separated & 1.27 & $(1.14-1.40)$ & 1.31 & $(1.18-1.45)$ \\
\hline & 1.12 & $(1.09-1.15)$ & 1.21 & $(1.18-1.23)$ \\
\hline \multicolumn{5}{|l|}{$\begin{array}{l}\text { Widowed } \\
\text { Race/ Ethnicity }\end{array}$} \\
\hline Non-Hispanic White & \multicolumn{2}{|c|}{ Reference } & \multicolumn{2}{|c|}{ Reference } \\
\hline African American & 0.69 & $(0.66-0.73)$ & 0.85 & $(0.81-0.89)$ \\
\hline American Indian & 0.68 & $(0.55-0.82)$ & 0.87 & $(0.72-1.05)$ \\
\hline Asian & 0.66 & $(0.62-0.71)$ & 1.22 & $(1.07-1.38)$ \\
\hline Hispanic & 0.68 & $(0.64-0.73)$ & 0.90 & $(0.84-0.95)$ \\
\hline Native Hawaiian/ Pacific Islander & 0.66 & $(0.50-0.87)$ & 0.80 & $(0.64-0.99)$ \\
\hline 2 or more race & 0.71 & $(0.59-0.86)$ & 1.35 & $(1.15-1.58)$ \\
\hline \multicolumn{5}{|l|}{ Chronic Conditions } \\
\hline Cancer & 0.83 & $(0.81-0.86)$ & 1.18 & $(1.15-1.20)$ \\
\hline COPD & 1.49 & $(1.45-1.53)$ & 1.20 & $(1.18-1.23)$ \\
\hline $\mathrm{CHF}$ & 0.72 & $(0.70-0.73)$ & 0.80 & $(0.78-0.81)$ \\
\hline Diabetes & 0.92 & $(0.90-0.94)$ & 0.97 & $(0.95-0.99)$ \\
\hline CKD & 0.49 & $(0.47-0.49)$ & 0.75 & $(0.73-0.76)$ \\
\hline Alzheimer's & 1.49 & $(1.44-1.54)$ & 1.45 & $(1.42-1.48)$ \\
\hline Dementia & 1.33 & $(1.30-1.37)$ & 1.24 & $(1.21-1.26)$ \\
\hline Alzheimer's Unit & 1.15 & $(1.11-1.20)$ & 1.14 & $(1.08-1.21)$ \\
\hline Hospice Unit & 1.05 & $(0.88-1.24)$ & 1.15 & $(0.83-1.59)$ \\
\hline \multicolumn{5}{|l|}{ Bed Size } \\
\hline 50-99 & \multicolumn{2}{|c|}{ Reference } & \multicolumn{2}{|c|}{ Reference } \\
\hline$<50$ & 1.16 & $(1.09-1.24)$ & 1.18 & $(1.10-1.28)$ \\
\hline 100-199 & 0.92 & $(0.90-0.95)$ & 0.82 & $(0.79-0.86)$ \\
\hline$>200$ & 0.81 & $(0.76-0.89)$ & 0.72 & $(0.67-0.77)$ \\
\hline
\end{tabular}

Note: CI: confidence interval. CHF: congestive heart failure; CKD: chronic kidney disease; COPD: chronic obstructive pulmonary disease; $\mathrm{NH}$ : nursing home; OR: odds ratio

All models controlled for state-level clustering effects, state-level fixed effects, sociodemographic characteristics (i.e., total ADL 
score), and facility level characteristics (i.e., staffing, occupancy rate, facility type, affiliation/chain status, setting, geographic region), county level characteristics (i.e., proportion of elderly, median household income)

\section{Figures}
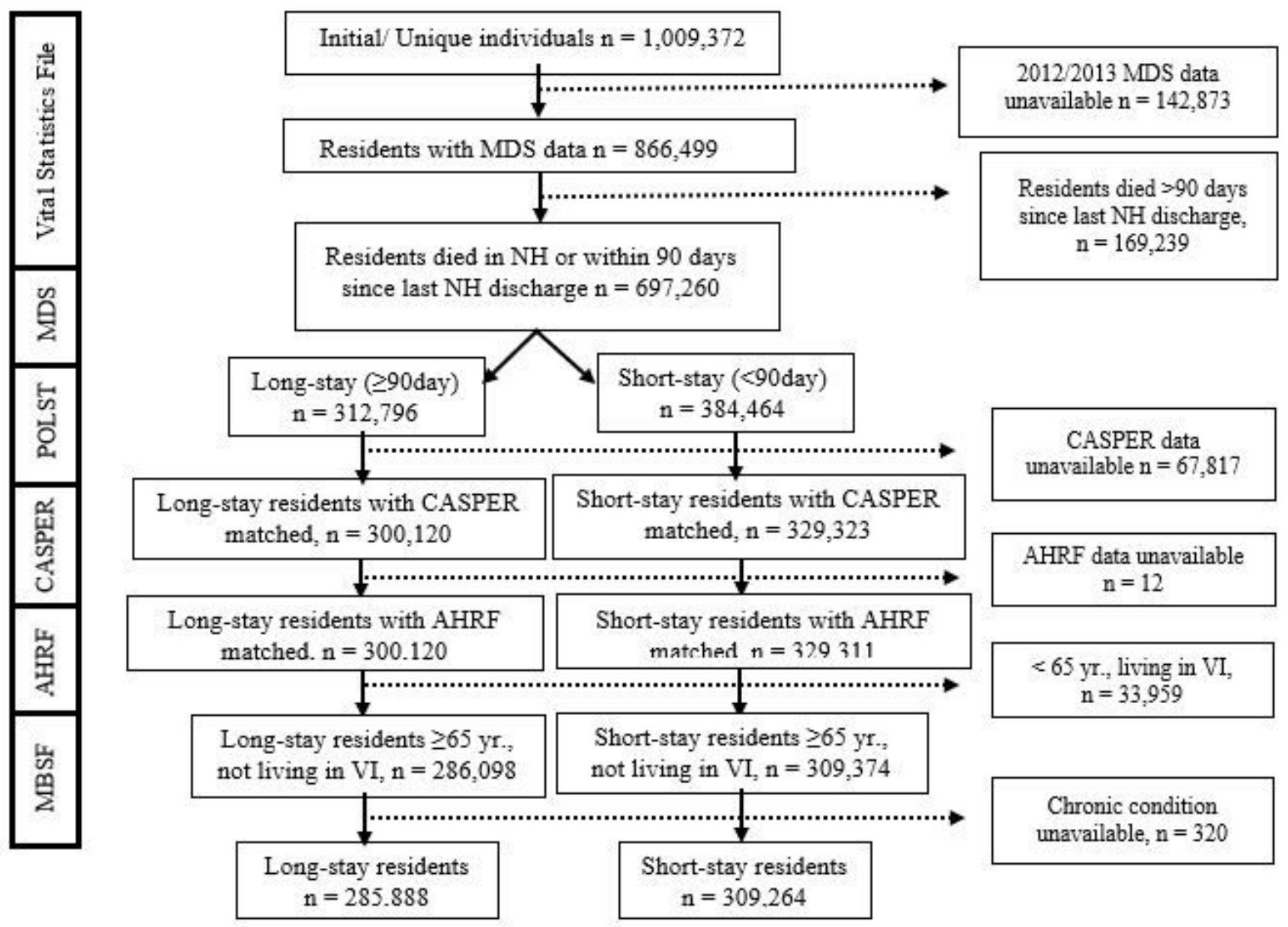

Figure 1

Sampling Process. Note: AHRF area health resource file; CASPER: certification and survey provider enhanced reports; MBSF: medical beneficiary summary file; MDS: minimum dataset; NH: nursing home; POLST: physician orders for life-sustaining treatment; VI: virgin island 